\title{
Estimated viability of greenhouse cooling technologies for growing a tomato crop under various climates
}

\author{
Yating Yang ${ }^{1,2}$, Shirong Guo ${ }^{2 *}$, Yongsheng Chen ${ }^{1}$ \\ (1. College of Horticulture, Nanjing Agricultural University, Jiangsu Province Engineering Lab for Modern Facility Agriculture Technology \\ \& Equipment, Nanjing 210095, China; \\ 2. Nanjing Institute of Agricultural Mechanization (NIAM), Ministry of Agriculture and Rural Affairs, Nanjing 210014, China)
}

\begin{abstract}
The viability of fan and natural ventilation, combined with evaporative cooling, was investigated using a simulation model and weather data for thirty-seven locations in the world (mostly in China). And the geographical distribution pattern of viable cooling technologies was examined in China. The model used was based on a simplified steady-state heat balance of a greenhouse, and weather data were from corresponding meteorological organizations. The evapotranspiration coefficient used two values of 0.5 and 1.0, and ventilation rates for natural ventilation were based on two empirically constructed equations. The results suggested that the viability of various cooling technologies depended largely on local weather, although evapotranspiration coefficient and ventilation characteristics of natural ventilation also played important roles. Some locations were sensitive to evapotranspiration coefficient and ventilation rate while some were not. The locations which were not sensitive to evapotranspiration coefficient and ventilation rate could choose the most economical technology to meet the cooling minimum, but these locations which were sensitive required evaporative cooling and/or forced ventilation. A detailed examination of the geographical pattern of viable cooling technologies was conducted for China. The results suggest that high altitude general provides a cooling advantage.
\end{abstract}

Keywords: climate, cooling, evaporative cooling, greenhouse, ventilation, viability, tomato

DOI: $10.25165 /$ j.ijabe.20211404.6134

Citation: Yang Y T, Guo S R, Chen Y S. Estimated viability of greenhouse cooling technologies for growing a tomato crop under various climates. Int J Agric \& Biol Eng, 2021; 14(4): 90-95.

\section{Introduction}

The selection of cooling technology for greenhouses is an important task for greenhouse investors and/or operators. Cooling needs are typically defined by the crop and local weather, and an appropriate cooling technology must be identified for providing those cooling needs. Various greenhouse cooling technologies exist based on some forms of ventilation. Ventilation can be achieved by fans (fan ventilation) in forced ventilation, or by pressure differences (wind) and/or inside-outside temperature differences (buoyancy) in natural ventilation. Evaporative cooling is a complementary technology providing additional cooling to assist transpirational cooling. Evaporative pads are normally used with fan ventilation, and fogging is generally paired with natural ventilation.

Each cooling technology has its limitations, and the viability of cooling technologies depends upon the weather, crop, investment amount, planting manager, among others. Nikolaou et al. ${ }^{[1]}$ examined cooling effects and cucumber growth under Mediterranean climate based on experiments and monthly weather data. The result showed the forced ventilation system in the

Received date: 2020-08-31 Accepted date: 2021-05-13

Biographies: Yating Yang, PhD candidate, Associate Professor, research interest: protected agricultural environment and mechanization engineering. Email: yangyating@caas.cn; Yongsheng Chen, Bachelor, Professor, research interest: protected agricultural mechanization engineering, Email: cys003@ sina.com.

*Correspondence: Shirong Guo, PhD, Professor, research interest: protected agricultural environment and vegetable physiology. College of Horticulture, Nanjing Agricultural University, Nanjing 210095, China. Tel: +86-2584395267, Email: srguo@njau.edu.cn. absence of an evaporative cooling could prevent overheating for cucumber. However, the system should be conjugated with an appropriate irrigation regime and required good management to reach a fine cooling effect. Ren et al. ${ }^{[2]}$ revealed fan-pad was a suitable cooling technology in east-central China by extensive CFD modeling and calculation. The majority of previous research about the cooling method in greenhouse has focused on modeling, CFD calculating, prototyping, and field trial to determine appropriate cooling technology under certain weather and crop. However, any method of research is uneconomical and infeasible for small and medium-sized vegetable production firms, which have taken tunnels and single-span plastic film greenhouses as main vegetable planting structures. Therefore, a simplified, adaptable, and validated method should be proposed for reducing investment and management costs by excluding unnecessary or improper cooling methods. That means a lot for small and medium-sized vegetable production firms in China.

Kittas $^{[3]}$ examined natural ventilation and fan ventilation under the climate of Greece based on monthly weather data and a set of rules he developed. However, evaporative cooling was not included in his analysis. Sun et al. ${ }^{[4]}$ tested cooling effect in a solar greenhouse during summer in Beijing by prototyping, and better cooling effect of forced ventilation with the evaporative pad was determined than natural ventilation. Neither force ventilation without pad nor natural ventilation with evaporative cooling was considered in the study. Because of the wind speed and ventilation rate away from the side wall installed fans were ineffective due to the long distance between the east and west wall under force ventilation without pad, and high air humidity limited the effectiveness of evaporative cooling under natural ventilation.

The purpose of this study was to evaluate the viability of 
two ventilation modes and their accompanying evaporative cooling technologies under different climates through a simplified and available model without massive computer calculation. Especially it can provide a useful and viable calculate method to exclude improper cooling technologies for reducing unnecessary investment in rural poor areas. The geographical pattern of viability is intended to be explored.

\section{Materials and methods}

\subsection{Simulation model}

The inside temperatures of greenhouses were predicted by the following model ${ }^{[5]}$ :

$$
t_{i}=t_{i n}+\frac{(1-E) \cdot \tau \cdot S_{o}}{\alpha \cdot U+\beta \cdot Q \cdot c_{p} \cdot \rho}
$$

where, $t_{i}$ is the inside temperature, ${ }^{\circ} \mathrm{C}$; $t_{i n}$ is the inlet temperature into greenhouse, ${ }^{\circ} \mathrm{C}$; $E$ is the evapotranspiration coefficient; $\tau$ is the transmissivity of greenhouse cover; $S_{o}$ is the outside solar radiation, $\mathrm{W} / \mathrm{m}^{2} ; \alpha$ is the cover-to-ground area ratio; $U$ is the overall heat transfer coefficient of greenhouse cover, $\mathrm{W} /\left(\mathrm{m}^{2} \cdot{ }^{\circ} \mathrm{C}\right) ; \beta$ is the adjustment coefficient for ventilation system; $Q$ is the ventilation rate, $\mathrm{m}^{3} /\left(\mathrm{m}^{2} \cdot \mathrm{s}\right) ; c_{p}$ is the specific heat of air, taken as $1007 \mathrm{~J} /\left(\mathrm{kg} \cdot{ }^{\circ} \mathrm{C}\right)$; $\rho$ is the density of outside air, taken as $1.157 \mathrm{~kg} / \mathrm{m}^{3}$ at $30^{\circ} \mathrm{C}$.

Temperatures resulting from evaporative pad cooling were expressed as following assuming wet bulb temperature is constant ${ }^{[6]}$.

$$
t_{i n}=t_{o}-\left(t_{o}-t_{w o}\right) \eta_{p}
$$

where, $t_{o}$ is the outside temperature, ${ }^{\circ} \mathrm{C}$; $t_{\text {wo }}$ is the outside wet bulb temperature, ${ }^{\circ} \mathrm{C} ; \eta_{p}$ is the cooling efficiency of evaporative pads, taken as 0.75 . If the evaporative pad was not in operation or if natural ventilation was used, $t_{i n}$ should be set equal to $t_{o}$.

For this study, the transmissivity of the greenhouse cover was set to 0.5 (the shading screen with $50 \%$ transmissivity was used commonly from May to September in China ${ }^{[7]}$ ) and the cover-toground area ratio was assumed to be 1.5. According to Seginer ${ }^{[5]}$, the adjustment coefficient, $\beta$, can be approximated as 1 for natural ventilation. Theoretically, the adjustment coefficient should be 2 if air temperature increased linearly along the airflow direction in fan ventilated greenhouses. Based on some unpublished experimental data, the coefficient was taken as 1.5 for fan ventilation. The deviation was attributed to the non-linearity of air temperature distribution in the direction of airflow. The lower value of $\beta$ is conservative, resulting in a slightly lower value of $t_{i}$ than that would be predicted using the coefficient suggested by Seginer ${ }^{[5]}$.

The evapotranspiration coefficient, $E$, depends on the type, amount, age, health, and/or stress level of the crops, the humidity ratio of the ventilation air at the inlet, and the amount of moisture available for evaporation from non-plant sources within the house $\mathrm{e}^{[8]}$. Originally, 0.5 was assumed to be a reasonable value for $E^{[9]}$. Later on, other studies ${ }^{[10,11]}$ found $E$ could be much higher than 0.5 , even greater than 1 . As of now, it is not clear how, and what extent, crop type and amount, humidity ratio of the incoming air, and other factors affect $E$. To deal with the uncertainty, two values of $E$ of 0.5 and 1.0 were selected to represent the range of conditions likely to be found in a greenhouse operation.

For fan ventilation, Willits ${ }^{[12]}$ suggested that increasing $Q$ beyond $0.05 \mathrm{~m}^{3} /\left(\mathrm{m}^{2} \cdot \mathrm{s}\right)$ is not beneficial for cooling if an evaporative pad is not used. Even when evaporative pads are used, operating with a $Q$ higher than $0.05 \mathrm{~m}^{3} /\left(\mathrm{m}^{2} \cdot \mathrm{s}\right)$ is not common. To be conservative, a slightly higher value of $0.06 \mathrm{~m}^{3} /\left(\mathrm{m}^{2} \cdot \mathrm{s}\right)$ was set for $Q$ for fan ventilation.

Various relationships between ventilation rates and wind speed have been developed previously for various vent configurations. Some of them are shown in Figure 1.

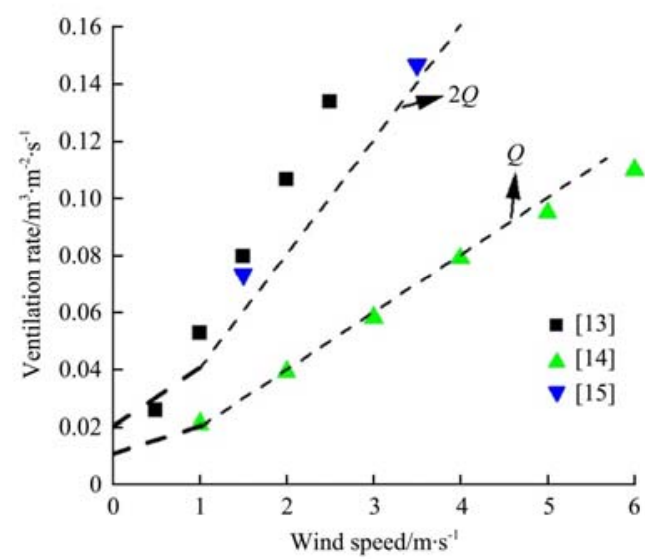

Note: $Q$ is ventilation rate, $\mathrm{m}^{3} /\left(\mathrm{m}^{2} \cdot \mathrm{s}\right)$.

Figure 1 Dependence of ventilation rate on wind speed ${ }^{[13-15]}$

To represent a moderate condition, the following relationship is constructed based on the data of Lee et al. ${ }^{[13]}$

$$
Q= \begin{cases}0.02 u & u \geq 1 \\ 0.01+0.01 u & u<1\end{cases}
$$

where, $u$ is the wind speed, $\mathrm{m} / \mathrm{s}$. Another ventilation rate was taken to be $2 Q$ to represent highly efficient natural ventilation systems, as suggested by the data of Kacira et al. ${ }^{[14,15]}$.

When fogging was used, the inside temperature should be calculated by the following equation ${ }^{[16,17]}$.

$$
t_{i}=t_{i}^{*}-\left(t_{i}^{*}-t_{w i}\right) \eta_{f}
$$

where, $t_{i}^{*}$ is the virtual inside temperature that would be reached without fogging, ${ }^{\circ} \mathrm{C}$; $t_{w i}$ is the inside wet bulb temperature, ${ }^{\circ} \mathrm{C} ; \eta_{f}$ is the cooling efficiency of fogging. The virtual temperature $t_{i}^{*}$ was calculated using Equation (1). The inside wet bulb temperature, $t_{w i}$, was correlated with inside enthalpy with the following relationship.

$$
t_{w i}=-0.0013 h_{i}^{2}+0.4527 h_{i}-2.1668
$$

where, $h_{i}$ is the inside enthalpy, $\mathrm{kJ} / \mathrm{kg}$. The relationship was regressed with the data points (wet bulb temperature versus enthalpy) calculated with a digital psychrometric chart ${ }^{[18]}$ within the range of wet-bulb temperatures of $5^{\circ} \mathrm{C}-38^{\circ} \mathrm{C}$ and at the relative humidity of $100 \%$. Figure 2 shows that the wet-bulb temperatures calculated with Equation (5) matched well with those calculated with the digital psychrometric chart.

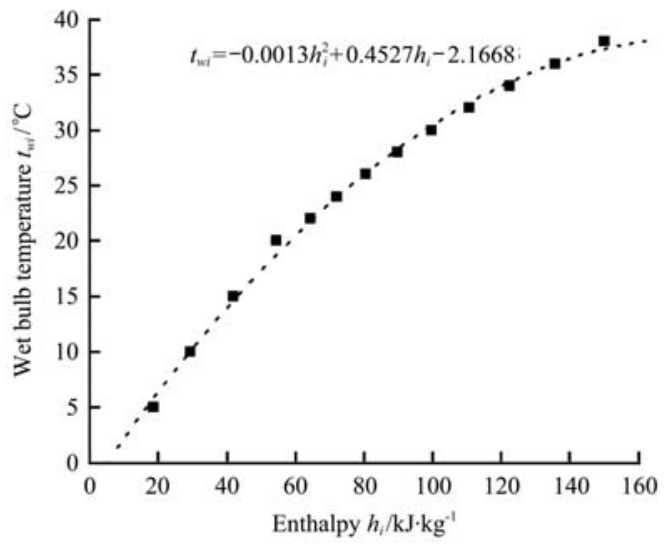

Figure 2 Regression relationship between enthalpy and wet bulb temperature 
The inside enthalpy, $h_{i}$, was approximated from a simplified heat balance as:

$$
h_{i}=h_{o}+\frac{\tau S_{o}}{Q \rho}
$$

The cooling efficiency of high-pressure fogging, $\eta_{f}$, is known to vary with spray rate, ventilation rate, and outside humidity ${ }^{[17]}$. To simplify this analysis, it was assumed to be a constant with a value of 0.5 .

\subsection{Locations and weather data}

Thirty locations in China and seven locations abroad were selected for analysis (Table 1 and Table 2). Each location selected from China has the lowest design wet-bulb temperature in its province $^{[18]}$ and weather data are available for that location. The selections of the most of locations in other countries were based on the rules of being close to major greenhouse production areas.

Weather data were derived from various sources. Weather data for China locations were from China Meteorological Administration. Weather data for the other countries were compiled by various agencies of the corresponding country and/or international meteorological organizations ${ }^{[19]}$.

Table 1 Viability index for all locations with different $E$ and $Q$ in China

\begin{tabular}{|c|c|c|c|c|c|}
\hline Province & City & A & B & $\mathrm{C}$ & $\mathrm{D}$ \\
\hline Tibet & Lhasa & 4 & 4 & 4 & 4 \\
\hline Yunnan & Kunming & 4 & 4 & 4 & 4 \\
\hline Ningxia & Yinchuan & 2 & 2 & 2 & 2 \\
\hline Liaoning & Shenyang & 2 & 2 & 2 & 2 \\
\hline Shanxi & Taiyuan & 2 & 2 & 2 & 2 \\
\hline Guizhou & Guiyang & 2 & 4 & 2 & 4 \\
\hline Heilongjiang & Harbin & 2 & 4 & 2 & 4 \\
\hline Jilin & Changchun & 2 & 4 & 2 & 4 \\
\hline Hebei & Shijiazhuang & 1 & 2 & 1 & 2 \\
\hline Shaanxi & Xi'an & 1 & 2 & 1 & 2 \\
\hline Sichuan & Chengdu & 1 & 2 & 1 & 2 \\
\hline Tianjin & Tianjin & 1 & 2 & 1 & 2 \\
\hline Beijing & Beijing & 1 & 2 & 1 & 2 \\
\hline Qinghai & Xining & 3 & 4 & 4 & 4 \\
\hline Gansu & Lanzhou & 1 & 2 & 2 & 2 \\
\hline Inner Mongolia & Hohhot & 1 & 2 & 2 & 2 \\
\hline Xinjiang & Urumqi & 2 & 2 & 2 & 2 \\
\hline Guangdong & Guangzhou & 1 & 1 & 1 & 1 \\
\hline Shanghai & Shanghai & 1 & 1 & 1 & 1 \\
\hline Hubei & Wuhan & 0 & 0 & 0 & 0 \\
\hline Anhui & Hefei & 0 & 1 & 0 & 1 \\
\hline Fujian & Fuzhou & 0 & 1 & 0 & 1 \\
\hline Guangxi & Nanning & 0 & 1 & 0 & 1 \\
\hline Hainan & Haikou & 0 & 1 & 0 & 1 \\
\hline Hunan & Changsha & 0 & 1 & 0 & 1 \\
\hline Jiangsu & Nanjing & 0 & 1 & 0 & 1 \\
\hline Jiangxi & Nanchang & 0 & 1 & 0 & 1 \\
\hline Zhejiang & Hangzhou & 0 & 1 & 0 & 1 \\
\hline Henan & Zhengzhou & 1 & 1 & 1 & 2 \\
\hline Shandong & Jinan & 1 & 1 & 1 & 2 \\
\hline
\end{tabular}

Note: A indicates that $E$ was 0.5 and $Q$ was from Equation (3); B indicates that $E$ was 1.0 and $Q$ was from Equation (3); C indicates $E$ was 0.5 and $Q$ was twice of that from Equation (3); D indicates that $\mathrm{E}$ was 1.0 and $\mathrm{Q}$ was twice of that from Equation (3), the same as below.
Table 2 Viability index for all locations with different $E$ and $Q$ abroad

\begin{tabular}{llllll}
\hline \multicolumn{1}{c}{ Country } & \multicolumn{1}{c}{ City } & A & B & C & D \\
\hline Canada & Vancouver & 4 & 4 & 4 & 4 \\
Netherlands & Amsterdam & 4 & 4 & 4 & 4 \\
Israel & Jerusalem & 2 & 4 & 2 & 4 \\
England & London & 2 & 4 & 4 & 4 \\
Spain & Almeria & 2 & 2 & 2 & 2 \\
Japan & Tokyo & 2 & 2 & 2 & 2 \\
Mexico & Mexico City & 1 & 4 & 3 & 4 \\
\hline
\end{tabular}

The weather data used were hourly values over 1 year. They include dry bulb temperature, relative humidity, horizontal solar radiation, and wind speed. Since summer cooling is the focus of this study, and all of the locations were in the northern hemisphere, only the data from May to September were used.

\subsection{Viability assessment}

The viability of the four cooling options (natural ventilation without fog, natural ventilation with fog, fan ventilation without evaporative pads, fan ventilation with evaporative pads) at the selected locations was assessed by calculating $t_{i}$ using the model described. The criteria for assessment were arbitrarily set to be that $98 \%$ of $t_{i}$ must be below $30.0^{\circ} \mathrm{C}$, otherwise, it was regarded as not viable. The temperature threshold of $30.0^{\circ} \mathrm{C}$ was arbitrarily based on a tomato crop ${ }^{[20]}$. Many crops have greater heat tolerance and some have less. If the crop were less heat tolerant than tomato, the results presented here would be re-evaluated.

To group the locations with the same suitable cooling number, a viability index is defined and tabulated in Table 3 . A ' 1 ' was used to indicate that a cooling option is suitable and a ' 0 ' indicates that a cooling option is undesirable. A four-bit number, each bit representing the viability of one of the four cooling options, characterized each location. $\mathrm{NV}$ in Table 3 meant natural ventilation while FV meant fan ventilation. And four cooling technologies are shown in Table 3, which are natural ventilation without high-pressure fog (NV+no fog), natural ventilation with high-pressure fog $(\mathrm{NV}+\mathrm{fog})$, fan ventilation without evaporative pad $(\mathrm{FV}+$ no pad), and fan ventilation with evaporative pad $(\mathrm{FV}+\mathrm{pad})$. A viability index with a value of 4 meant that all the four cooling options are viable; an index with a value of 3 meant that all the four cooling options except NV without fog are viable; an index equal to 2 meant that $\mathrm{NV}$ with fog and FV with the pad is suitable while $\mathrm{NV}$ without fog and FV without pad is not viable, and so forth.

Table 3 Definition of viability index

\begin{tabular}{ccccc}
\hline NV+no fog & NV+fog & FV+no pad & FV+pad & Viability index \\
\hline 1 & 1 & 1 & 1 & 4 \\
0 & 1 & 1 & 1 & 3 \\
0 & 1 & 0 & 1 & 2 \\
0 & 0 & 0 & 1 & 1 \\
0 & 0 & 0 & 0 & 0
\end{tabular}

To examine the sensitivity of the suitability index to $E$ and $Q$, the suitability assessment was performed with four calculation conditions with different $E$ and $Q$. The four conditions were denoted as A, B, C and D (Table 1 and Table 2). Condition A represented an $E$ of 0.5 and a $Q$ calculated with Equation (3); Condition B represented an $E$ of 1.0 and $Q$ calculated with Equation (3); Condition C represented an $E$ of 0.5 and a $Q$ two times greater than Equation (3); Condition D represented an $E$ of 
1.0 and a $Q$ two times greater than Equation (3).

\section{Results}

\subsection{Viability of various cooling options under different} conditions

\subsubsection{Consistent pattern}

The viability of the various cooling options for the selected locations is given in Table 1 and Table 2. Thirteen locations had consistent viability indices in spite of different conditions, including four locations abroad. For example, the index for Kunming (Yunnan) is 4, indicating all four cooling technologies are appropriate to meet the desired cooling. In other words, natural ventilation without any evaporative cooling would be sufficient for Kunming (Yunnan). Another example is Shenyang (Liaoning) which has an index of 2, meaning that evaporative cooling, either fog or evaporative pad, must be used to provide the cooling minimums established in this study. Similar results were obtained in other studies ${ }^{[21,22]}$. For example, Guangzhou (Guangdong) has an index of 1 , which means that both forced ventilation and evaporative pad should be used at the same time, namely neither natural ventilation nor high-pressure fog could provide sufficient cooling minimums according to this study. The result was similar to the conclusion that $\mathrm{FV}+$ evaporative pad could decrease the temperature to $3.8^{\circ} \mathrm{C}$ indoor while fogging and nature ventilation increase temperature by $2.5^{\circ} \mathrm{C}$ and $4.7^{\circ} \mathrm{C}$ indoors separately $^{[23]}$.

The other extreme are the locations with an index of 0 , where none of the cooling options were viable. The location is Wuhan (Hubei). Additional cooling (such as shading with lower transmissivity, even air condition) will be required for these locations to meet the cooling needs specified in this study.

\subsubsection{N-shaped pattern}

Seventeen locations had consistent trends along with $E$ and $Q$ trends (Table 1 and Table 2), and the index of these locations shows vertical zigzag curves under conditions A, B, C, and D. For example, locations such as Guiyang, Harbin, Changchun in
China and Jerusalem in Israel require evaporative cooling if $E$ were 0.5 but not if $E$ were 1.0, meaning the importance of evaporative cooling. Another example, locations of Shijiazhuang (Hebei), Xi'an (Shaanxi), Chengdu (Sichuan), Tianjin (Tianjin), and Beijing (Beijing) had an index of 1 if $E$ were 0.5 and an index of 2 if $E$ were 1.0, which meant natural ventilation with high-pressure fog cannot cool minimally. In another study about how to enhance the cooling effects of wet curtains, installing large volume fans to increase ventilation rate was recommended because of insufficient cooling of natural ventilation with fogging ${ }^{[24]}$, which was coincident with the result in this study.

As for the other locations, such as Hefei (Anhui), Fuzhou (Fujian), Nanning (Guangxi) and so on, there was only FV+pad suitable if $E$ were 1.0, and even no right cooling method if $E$ were 0.5 . Xu et al. ${ }^{[25]}$ suggested a proper pad area and ventilation rate under different greenhouse lengths by complex CFD simulation, and the result was coincident with that the greenhouse at Hangzhou need $\mathrm{FV}+$ pad cooling when $E$ was 1.0 according to this research.

3.1.3 Other variety of viability

Viability indices of other locations varied with $E$ and $Q$. For locations such as Lanzhou in China and Hohhot in Inner Mongolia, only FV+pad was a viable cooling option under Condition A; however, both $\mathrm{FV}+$ pad and $\mathrm{NV}+$ fog provided sufficient cooling under Conditions B, C, and D.

\subsection{Geographical distribution pattern}

Figure 3 shows the geographical distribution pattern of the viability index under Condition $\mathrm{B}$, which indicates that $E$ was 1.0 and $Q$ was from Equation (3). Six locations in China had an index of 2 and $\mathrm{NV}+$ no fog there could provide the specified cooling. The locations in China were mainly concentrated in the southwest and northeast. High altitude often provides a cooling advantage. For example, the city of Kunming lies in the south of China, where the climate is semi-tropical. And owing to its high altitude $(1892 \mathrm{~m})$, the temperature in summer is much lower than that in other cities at the same latitude. The monthly average temperatures at noon in July are $22^{\circ} \mathrm{C}-23^{\circ} \mathrm{C}$.

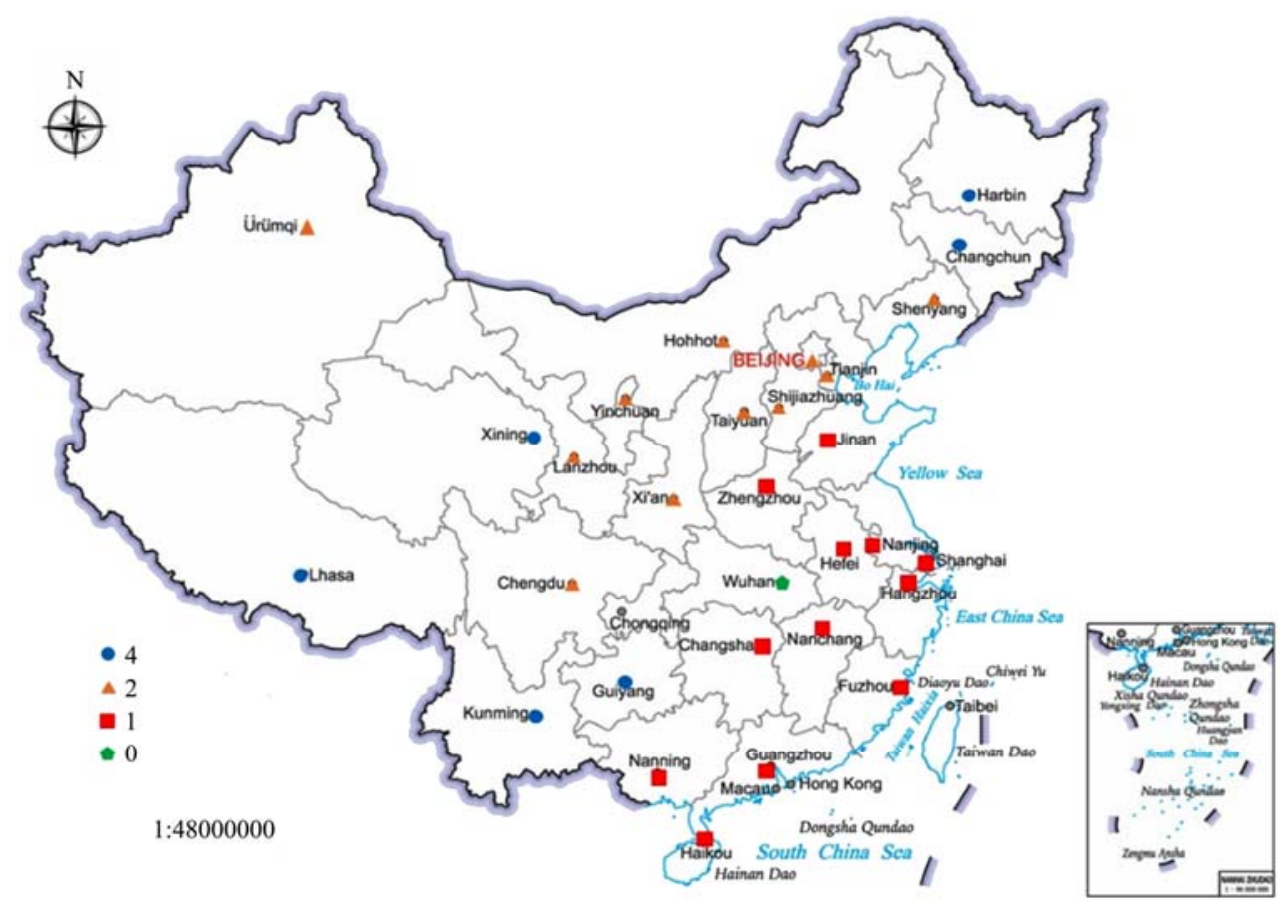

Note: '4' indicates that natural ventilation without fog is suitable; '2 'indicates both fan and pad system and natural ventilation with high-pressure fog are suitable; ' 1 ' indicates that only fan-and-pad system is suitable; ' 0 ' means neither of the cooling options is suitable.

Figure 3 Suitability indices for China under Condition B 
Eleven locations had an index of 2. The China locations were mainly concentrated on the northern, suggesting the two evaporative cooling technologies (evaporative pads or fogging) were necessary to meet the cooling needs for most conditions due to fair air humidity. Most locations with an index of 0 or 1 in China were located in the coastal area and southeast, where summer cooling is generally more demanding than other areas of China.

\section{Discussion}

These results suggest that whether the cooling technologies are viable for a location is largely determined by the geographic position and local climate, but it is also affected by crop statuses such as transpiration rate and greenhouse characteristics such as ventilation options design. The validity of these results relies on the parameters and cooling criterion selected. Based on the response of the viability index to $E$, it is obvious that plant transpiration plays an important role in greenhouse cooling.

In spite of the uncertainty surrounding the parameters $E$ and $Q$, the method illustrated in this study allowed a simple assessment of cooling options without mass data and modeling, and a greenhouse cooling design method from a different perspective without complex simulation and calculation. For example, the locations of Shijiazhuang (Hebei) and some other cities had indices of 1, 2, 1, and 2 separately under the conditions of A, B, C, and D, namely the index was changed from 2 to 1 while $E$ was changed from 1.0 to 0.5. It indicated that the decline of evapotranspiration led to more demand for cooling both ventilation and evaporation. Another similar example is locations of Guiyang (Guizhou) and some other cities had indices of 2, 4, 2, and 4 separately under the conditions of A, B, C, and D. In other words, the index was changed from 4 to 2 while $E$ was changed from 1.0 to 0.5 . It meant that it was necessary for evaporative cooling for these cities which were more sensitive to $E$ than $Q$. Thus, evaporative cooling options, either an evaporative pad or fogging, are recommended at these locations when the greenhouse was designed.

The normal design procedure utilizes the design conditions, such as temperature and available solar radiation, given in engineering standards such as the HVAC data manual and applies them to design equations to specify equipment capacities. The design conditions are usually statistically derived from raw weather data, representing the harshest conditions. However, the harshest condition for every concerned variable does not normally occur at the same time. On the other hand, designs based on the extreme conditions for individual variables tend to be conservative if the correlation between the variables is not considered. So, if the weather is regarded as random and raw weather data can represent its distribution reasonably, applying weather data to a thermal system and ensuring the design variables remain below the desired level should result in more reasonable designs.

\section{Conclusions}

The viability of fan and natural ventilation, combined with evaporative cooling, was investigated using a simulation model for thirty-seven locations in the world, mostly in China. And the geographical distribution pattern of viable cooling technologies was examined in China. The model was based on a simplified steady-state heat balance model of greenhouse cooling. The results suggest that the viability of the various cooling technologies is largely determined by local climate and altitude. Evapotranspiration coefficient and ventilation characteristics of natural ventilation were also shown to be important factors. The locations with a consistent viability index could choose the most economical technology to meet the cooling minimum. Some locations were especially sensitive to the evapotranspiration coefficient and the ventilation characteristics, so these locations with zigzag viability index required evaporative cooling and/or forced ventilation.

\section{Nomenclature}

\begin{tabular}{ll}
\hline$c_{p}$ & Specific heat of air, $\mathrm{J} /\left(\mathrm{kg} \cdot{ }^{\circ} \mathrm{C}\right)$ \\
$E$ & Evapotranspiration coefficient \\
$h_{i}$ & Inside enthalpy, $\mathrm{kJ} / \mathrm{kg}$ \\
$h_{o}$ & Outside enthalpy, $\mathrm{kJ} / \mathrm{kg}$ \\
$Q$ & Ventilation rate, $\mathrm{m}^{3} /\left(\mathrm{m}^{2} \cdot \mathrm{s}\right)$ \\
$S_{o}$ & Outside solar radiation, $\mathrm{W} / \mathrm{m}^{2}$ \\
$t_{i}$ & Inside temperature, ${ }^{\circ} \mathrm{C}$ \\
$t_{i}^{*}$ & Inside temperature that would be reached without fog, ${ }^{\circ} \mathrm{C}$ \\
$t_{i n}$ & Inlet temperature into greenhouse, ${ }^{\circ} \mathrm{C}$ \\
$t_{o}$ & Outside temperature, ${ }^{\circ} \mathrm{C}$ \\
$t_{w o}$ & Outside wet bulb temperature, ${ }^{\circ} \mathrm{C}$ \\
$t_{w i}$ & Inside wet bulb temperature, ${ }^{\circ} \mathrm{C}$ \\
$U$ & Overall heat transfer coefficient of greenhouse cover, $\mathrm{W} /\left(\mathrm{m}^{2} \cdot{ }^{\circ} \mathrm{C}\right)$ \\
$u$ & Wind speed, m $/ \mathrm{s}$ \\
$\alpha$ & Cover-to-ground area ratio \\
$\beta$ & Adjustment coefficient for ventilation system \\
$\rho$ & $\quad$ Density of outside air, kg/m ${ }^{3}$ \\
$\eta_{p}$ & Transmissivity of greenhouse cover \\
$\eta_{f}$ & Cooling efficiency of evaporative pad \\
\hline &
\end{tabular}

\section{Acknowledgements}

The authors acknowledge that this work was financially supported by the National Key Research and Development Program of China (Grant No. 2017YFD0201607), the China Agriculture Research System (CARS-23-B12).

\section{[References]}

[1] Nikolaou G, Neocleous D, Katsoulas N, Kittas C. Effects of cooling systems on greenhouse microclimate and cucumber growth under Mediterranean climatic conditions. Agronomy, 2019; 9(6): 300. doi: 10.3390/agronomy9060300.

[2] Ren S G, Yang W, Wang H Y, Xue W, Xu H L, Xiong Y J. Prediction model on temporal and spatial variation of air temperature in greenhouse and ventilation control measures based on CFD. Transactions of the CSAE, 2015; 31(13): 207-214. (in Chinese)

[3] Kittas C. A simple climagraph for characterizing regional suitability for greenhouse cropping in Greece. Agricultural and Forest Meteorology, 1996; 78(1-2): 133-141.

[4] Sun W T, Zhou B, Xu F, Shang C, Lu C G, Guo W Z. Performance of positive pressure fan-pad cooling system and cooling load model for Chinese solar greenhouse. Transactions of the CSAE, 2019; 35(16): 214-224.

[5] Seginer I. Alternative design formulae for the ventilation rate of greenhouses. Journal of Agricultural Engineering Research, 1997; 68(4): 355-365.

[6] Koca R W, Hughes W C, Christianson L L. Evaporative cooling pads: Test procedure and evaluation. Applied Engineering in Agriculture, 1991; 7(4): 485-490.

[7] Ding X M, Zhou C J. Test and measurement of solar visible radiation transmittance of greenhouse glazing. Transactions of the CSAE, 2008; 24(8): 210-213. (in Chinese)

[8] ANSI/ASAE EP406.2. Standard ASABE. Heating, ventilating and cooling greenhouses, St. Joseph, Michigan, USA: ASAE, 2008. 
[9] Albright L D. Environment control for animals and plants.: St. Joseph, Michigan, USA: ASAE, 1991; 276p.

[10] Katsoulas N, Baille A, Kittas C. SE-Structures and Environment: Influence of leaf area index on canopy energy partitioning and greenhouse cooling requirements. Biosystems Engineering, 2002; 83(3): 349-359.

[11] Willits D H. Fan ventilated greenhouses cooling: Some considerations for design. Acta Horticulturae, 2006; 719: 83-96.

[12] Willits D H. Cooling fan ventilated greenhouses: a modeling study. Biosystems Engineering, 2003; 84(3): 315-329.

[13] Lee I, Short T H. Two-dimensional numerical simulation of natural ventilation in a multi-span greenhouse. Transactions of the ASAE, 2000; 43(3): 745-753.

[14] Kacira M, Sase S, Okushima L. Optimization of vent configuration by evaluating greenhouse and plant canopy ventilation rates under wind-induced ventilation. Transactions of the ASAE, 2004; 47(6): 2059-2067.

[15] Kacira M, Sase S, Okushima L. Effect of side vents and span numbers on wind-induced natural ventilation of a gothic multi-span greenhouse. Japan Agricultural Research Quarterly, 2004; 38(4): 227-233.

[16] Bottcher R W, Baughman G R, Gates R S, Timmons M B. Characterizing efficiency of misting systems for poultry. Transactions of the ASAE, 1991; 34(2): 586-590.

[17] Li S, Willits D H, Yunker C. Experimental study of a high-pressure fogging system in naturally ventilated greenhouses. Acta Horticulturae, 2006; 719, 393-400.
[18] Guan W J. HVAC data manual. Beijing: China Architecture \& Building Press, 2016; pp.256-279.

[19] Department of Energy. 2006. Available: http://www.eere.energy.gov/ buildings/energyplus/cfm/weather_data.cfm. Accessed on [2020-7-15].

[20] Li S, Guo S. Protected horticulture. Beijing: China Agriculture Press, 2002; 179p.

[21] Liu Y J, Xu J T, Pang S R, Sun Z P, Li T L. Design of positive-pressure wet curtain fan system for solar greenhouse and its cooling effects. Journal of China Agricultural University, 2019; 24(5): 130-139. (in Chinese)

[22] Wang T L, Li T L, Bai Y K, Yu W. Experimental research on the application of wet screen- air blower cooling. Journal of Shenyang Agricultural University, 2007; 38(6): 837-840. (in Chinese)

[23] Liu Y H. Greenhouse thermo-hygro environment character in greenhouse in southern China during summer. In: Study on regulation mechanism of greenhouse thermo-hygro environment in southern China during summer. Doctoral dissertation. Guangzhou: South China University of Technology, 2017; pp.21-29. (in Chinese)

[24] Chen Z H, Ren F J, Yu T, Tang M, Jiang R X, Liu J J, et al. Analysis of ventilation and cooling effects of installing axial fans in wet curtain cooling dairy cattle barn. Transactions of the CSAE, 2021; 37(5): 198-208. (in Chinese)

[25] Xu F, Cai Y W, Chen J L, Zhang L B. Temperature/flow field simulation and parameter optimal design for greenhouses with fan-pad evaporative cooling system. Transactions of the CSAE, 2015; 31(9): 201-208. (in Chinese) 